\title{
Impact of Proline and Aspartic Acid Residues on the Dissociation of Intermolecularly Crosslinked Peptides
}

\author{
Myles W. Gardner and Jennifer S. Brodbelt \\ Department of Chemistry and Biochemistry, The University of Texas at Austin, Austin, Texas, USA
}

\begin{abstract}
The dissociation of intermolecularly crosslinked peptides was evaluated for a series of peptides with proline or aspartic acid residues positioned adjacent to the crosslinking sites (lysine residues). The peptides were crosslinked with either disuccinimidyl suberate (DSS) or disuccinimidyl L-tartrate (DST), and the influence of proline and aspartic acid residues on the fragmentation patterns were investigated for precursor ions with and without a mobile proton. Collisionally activated dissociation (CAD) spectra of aspartic acid-containing crosslinked peptide ions, doublycharged with both protons sequestered, were dominated by cleavage C-terminal to the Asp residue, similar to that of unmodified peptides. The proline-containing crosslinked peptides exhibited a high degree of internal ion formation, with the resulting product ions having an $\mathrm{N}$-terminal proline residue. Upon dissociation of the doubly-charged crosslinked peptides, twenty to fifty percent of the fragment ion abundance was accounted for by multiple cleavage products. Crosslinked peptides possessing a mobile proton yielded almost a full series of b- and y-type fragment ions, with only proline-directed fragments still observed at high abundances. Interestingly, the crosslinked peptides exhibited a tendency to dissociate at the amide bond C-terminal to the crosslinked lysine residue, relative to the $\mathrm{N}$-terminal side. One could envision updating computer algorithms to include these crosslinker specific product ions-particularly for precursor ions with localized protons-that provide complementary and confirmatory information, to offer more confident identification of both the crosslinked peptides and the location of the crosslink, as well as affording predictive guidelines for interpretation of the product-ion spectra of crosslinked peptides. (J Am Soc Mass Spectrom 2008, 19, 344-357) (c) 2008 American Society for Mass Spectrometry
\end{abstract}

$\mathrm{W}$ ith tremendous advances in proteomics in the past decade, the interest in understanding protein-protein interactions at a molecular level has expanded as new methods for exploring macromolecules have emerged [1-3]. Chemical crosslinking of proteins coupled with mass spectrometric analysis has become a more widely used method for determining protein-protein interactions in recent years [4-6]. Protein crosslinking is a low-resolution, structural analysis technique that allows one to determine distance constraints within single proteins $[7,8]$, or protein-ligand complexes [9-13]. Crosslinked proteins are typically subjected to enzymatic digestion to create more easily interpreted peptide segments upon subsequent tandem mass spectrometric analysis. Crosslinking has also been utilized to identify protein folds [6], conformational changes of proteins upon activation [14, 15], and RNA-protein interactions [16]. While the chemical crosslinking experiment is often rather straightforward, the technique is restricted by several limitations which must be overcome to obtain the desired structural information. First, the crosslinked pep-

Address reprint requests to Dr. J. S. Brodbelt, Department of Chemistry and Biochemistry, The University of Texas at Austin, 1 University Station A5300, Austin, TX 78712, USA. E-mail: jbrodbelt@mail.utexas.edu tides must be identified from unmodified ones, typically in complex mixtures such as enzymatic digests of the protein or protein-complexes, in which there may only be a few crosslinks per protein among an abundance of unmodified peptide fragments. Once distinguished and identified, collisionally activated dissociation (CAD) experiments on these species are performed to sequence the peptide or peptides. Structural assignment of the crosslinked peptides is still not routine despite the emergence of several sequencing algorithms [17-22]. In fact, one of the main pitfalls of mass spectrometric strategies for examination of crosslinked peptides is the lack of comprehensive rules for interpretation of the product ion spectra. Finally, with the known sequence tags, the site and residue of chemical modification must be pinpointed to estimate distance constraints.

Despite the enormous number of investigations that have elucidated the fragmentation pathways of conventional tryptic peptides, to date only a few studies have focused on mapping the dissociation trends of crosslinked peptides in a systematic fashion [20, 23, 24]. Initial work by Schilling et al. demonstrated that dissociation of intermolecularly crosslinked peptides typically resulted in amide bond cleavage of one peptide, with the crosslink and second peptide acting as a modification [20]. In addition, 
they observed product ions unique to crosslinked peptides, including two cleavage fragment ions such as $b / b$ ions, in which two b-type fragment ions were linked together. A more recent study investigating the effects of lysine specific crosslinkers and precursor ion charge observed that without a mobile proton, many of the product ions formed were not of the a-, b-, or y-type [23]. Gaucher et al. also noticed that intramolecularly crosslinked peptides exhibited enhanced dissociation at the peptide amide bonds adjacent to the crosslinked lysine residues [23].

While many fundamental studies and statistical analyses have examined the influence of amino acid content on the gas-phase dissociation of unmodified peptides [25-29], no similar work to date has been performed for crosslinked peptides. It has been shown that certain amino acids, including aspartic acid and proline, enhance or promote specific backbone cleavage of peptides [30-38]. The mobile proton model, which proposes that peptide fragmentation is driven by chargedirected cleavages, has shown that higher energies are required to dissociate peptide ions in which the protons are sequestered at basic sites, particularly arginine residues [26, 30, 38-40]. For such peptides which do not possess a mobile proton and have aspartic acid residues, enhanced cleavage at the Asp-Xxx bond has been observed [31, 41,42]. Work by the Wysocki group has demonstrated that the acidic side-chain of aspartic acid directs fragmentation, site-specifically, at the C-terminal amide bond [33, 43]. Similar dissociation trends were also observed for glutamic acid containing peptides [33]. Proline residues enhance dissociation Nterminally, at the Xxx-Pro amide bond, often yielding intense $y$-type ions, and has been observed for the dissociation of small, singly-charged peptides as well as multiply-charged proteins [32, 44]. This site-specific cleavage was first attributed to the high gas-phase basicity of the proline residue [45], but has also been theorized to be due to unfavorable ring strain of a proposed bicyclic structure of the b-type ion that would be formed upon cleavage C-terminal to the proline [46].

The effects of amino acid content on the gas-phase fragmentation of crosslinked peptides, in particular residues which are known to promote site-specific dissociation along the peptide backbone, have not been analyzed. Knowledge of the dissociation trends of crosslinked peptides, especially with regards to specific amino acids, would be useful for improving computer algorithms to aid in the interpretation of product ion spectra of these ions. In this work, we investigate the influence of aspartic acid and proline on the dissociation of intermolecularly crosslinked peptides. As unmodified peptides tend to exhibit enhanced fragmentation C-terminally to aspartic acid residues for precursor ions with sequestered protons, and N-terminally to prolines, these residues were positioned adjacent to the lysines modified by commonly used primary aminespecific crosslinkers. The impact of these residues on the directionality of cleavage relative to the crosslinked lysine is also reported.

\section{Experimental}

\section{Reagents}

The following five peptides were synthesized at the Protein Microanalysis Facility at the University of Texas at Austin and purified by reversed-phase liquid chromatography: Ac-AAAKAAAAR (AKA), Ac-AADKAAAAR (DKA), Ac-AAAKDAAAR (AKD), Ac-AAPKAAAAR (PKA), and Ac-AAAKPAAAR (AKP). The peptides neurotensin (Pyr-LYENKPRRPYIL) and $\alpha$-MSH (Ac-SYSMEHFRWGKPV-NH ${ }_{2}$ ) were purchased from Bachem (Torrance, CA). The crosslinker disuccinimidyl suberate (DSS) was purchased from SigmaAldrich (St. Louis, MO), and disuccinimidyl L-tartrate (DST) from Toronto Research Chemicals (North York, Ontario, Canada). All other chemicals and solvents were obtained from Fisher Scientific (Fairlawn, NJ) except for extra dry dimethylsulfoxide (DMSO) (SigmaAldrich).

\section{Chemical Crosslinking}

Stock solutions of each peptide were prepared at $5.0 \mathrm{mM}$

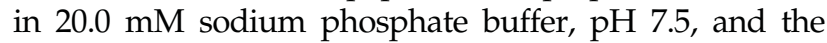
crosslinkers were freshly prepared at $20.0 \mathrm{mM}$ in DMSO directly before use. The crosslinking reaction was performed by adding $8.0 \mu \mathrm{L}$ of each peptide to $2.5 \mu \mathrm{L}$ of crosslinker, for a molar ratio of 4:4:5 ( $\alpha$ peptide: $\beta$ peptide: crosslinker). The reaction was allowed to proceed at room temperature for $1 \mathrm{~h}$, after which the reaction mixture was desalted by solid-phase extraction using $50 \mathrm{mg} \mathrm{tC} \mathrm{t}_{18}$ Waters (Milford, MA) Sep-Pak cartridges.

\section{Methods and Instrumentation}

Samples were diluted to a concentration of $20 \mu \mathrm{M}$ in 70/30/1 $\mathrm{MeOH} / \mathrm{H}_{2} \mathrm{O} / \mathrm{HOAc}$ (vol/vol/vol) for ESI-MS analysis. Experiments were performed on a ThermoFinnigan LCQ Duo (San Jose, CA) quadrupole ion trap with the standard electrospray source. Solutions were infused into the mass spectrometer at $3 \mu \mathrm{L} / \mathrm{min}$ using a Harvard Apparatus PHD 2000 syringe pump (Holliston, MA). Ionization and ion optic conditions were optimized once for each precursor charge state and were not retuned for each individual crosslinked peptide pair. Precursor ions were activated for $30 \mathrm{~ms}$ at the typical $\mathrm{q}_{\mathrm{z}}$ value of 0.25 for CAD and the collision energy was adjusted such that precursor ion abundance was less than $10 \%$ of the total ion abundance. Typical CAD energies for doubly-charged crosslinked peptide ions ranged from 1.08 to $1.24 \mathrm{~V}(\sim 30 \%$ normalized collision energy), and 0.57 to $0.62 \mathrm{~V}$ ( $\sim 20 \%$ normalized collision energy) for the triply-charged species. The precursor ion isolation window was set to $4 \mathrm{~m} / \mathrm{z}$ units to retain isotopic profile to aid in determining the charge state of the product ions. For some of the doublycharged crosslinked peptides, the activation $\mathrm{q}_{\mathrm{z}}$-value was decreased to 0.22 from 0.25 to effectively trap the 
low-mass $b_{3}$ fragment ion; the dissociation efficiency and fragment ion abundances were not significantly affected by this change. All collisionally activated dissociation experiments were collected in triplicate.

\section{Data Analysis}

Relative product ion abundances were calculated by dividing each product ion peak area by the total fragment ion abundance. Fragment ions were grouped into different product ion types: $\mathrm{y}$-ions, $\mathrm{b}$ and a-ions, crosslink amide bond cleavage products, lysine immonium ions, internal ions, other double cleavage products $(b / b, b / y$, and $y / y)$, and specific crosslinker cleavage products (e.g., dissociation of the $\mathrm{C} 7-\mathrm{C} 8$ bond of DST). Peaks were defined as having a minimum relative intensity of $1 \%$ and a minimum area of $0.1 \%$ of the total area in the spectrum. Water and ammonia losses from each product ion type were included in the corresponding base group (e.g., peak area of a $\mathrm{y}_{n}-\mathrm{NH}_{3}$ ion were included in the y-ion group). Neutral losses including water, ammonia, and $\mathrm{CO}_{2}$ from the precursor ion were excluded from the total fragment ion abundance for simplicity. To determine the effect of Asp and Pro residues in regards to cleavage at the site of crosslinking, K4, the directionality of cleavage bias to the lysine residue was calculated for both the crosslinked peptides and the unmodified species using a method previously suggested by Tabb et al. [28]. The C-terminal cleavage bias was determined by taking the ratio of the difference in C-terminal and $\mathrm{N}$-terminal fragment ions, relative to the lysine residue, to the sum of these fragment ion peak areas. For example, the y-ion C-terminal bias was calculated as follows:

$$
C_{y}=\frac{\left(A_{y 5 \kappa}+A_{y 5 \beta}\right)-\left(A_{y 6 \sigma}+A_{y 6 \beta}\right)}{\left(A_{y 5 \alpha}+A_{y 5 \beta}\right)+\left(A_{y 6 \alpha}+A_{y 6 \beta}\right)}
$$

where $A_{i}$ is the peak area of the respective y-ions; the $\mathrm{y}_{6}$ ions are products of cleavage $\mathrm{N}$-terminal to the crosslinked lysine, and the $\mathrm{y}_{5}$ ions are a result of $C$-terminal cleavage for the nine-residue peptides analyzed in this study. The $\alpha$ and $\beta$ subscripts refer to cleavage of the $\alpha$ and $\beta$ peptides, respectively, and are explained in more detail in the results and discussion. A positive value indicates a fragmentation bias Cterminally to the lysine residue, whereas a negative value signifies an N-terminal bias. Similarly, for the b-ions, the cleavage bias was calculated using the following formula:

$$
C_{b}=\frac{\left(A_{b 4 \alpha}+A_{b 4 \beta}\right)-\left(A_{b 3 \alpha}+A_{b 3 \beta}\right)}{\left(A_{b 4 \alpha}+A_{b 4 \beta}\right)+\left(A_{b 3 \varkappa}+A_{b 3 \beta}\right)}
$$

where the $\mathrm{b}_{4}$ ions are the $\mathrm{C}$-terminal cleavage products and the $b_{3}$ ions are the $\mathrm{N}$-terminal fragments.<smiles>O=C(CCCCCCC(=O)ON1C(=O)CCC1=O)ON1C(=O)CCC1=O</smiles><smiles>O=C(ON1C(=O)CCC1=O)C(O)C(O)C(=O)ON1C(=O)CCC1=O</smiles>

Scheme 1

\section{Results and Discussion}

The dissociation of crosslinked peptides containing either a proline or an aspartic acid residue was investigated to determine if these species follow similar fragmentation pathways as unmodified peptides. Poly-alanine sequences were used as "filler" residues to minimize competing fragmentation pathways. The peptides were crosslinked with either DSS or DST (Scheme 1), two widely used crosslinkers which react with primary amines such as free $\mathrm{N}$-termini or the $\varepsilon$-amine of lysine residues. Since the $\mathrm{N}$-termini of these peptides were acetylated, it can be assumed that the site of crosslinking is between $\mathrm{K} 4$ of each peptide. A proline or aspartic acid residue was positioned on either the C- or N-terminal side of the crosslinked lysine to determine whether the crosslink influenced the dissociation trends of the peptides containing either of these two residues. The resulting doubly-charged crosslinked peptides are assumed to have both protons sequestered on the C-terminal arginine residues [30], whereas the triply-charged species possess a mobile proton. The crosslinked peptides in both the $2+$ and $3+$ charge states were analyzed by CAD to compare the effects of the proline or aspartic acid residues in different charge states. The product ions formed were labeled according to the nomenclature suggested in references [20] and [23]. In brief, the two intermolecularly crosslinked peptides are labeled $\alpha$ and $\beta$, referring to the first and second peptide listed, respectively. Cleavage along the backbone of the $\alpha$ peptide yielding a b-ion is labeled as $b_{n \alpha}$ and similar notation is used other fragment ion types, as well as for the $\beta$ peptide. Product ions of both peptides crosslinked together are labeled with the fragmentation nomenclature for each cleavage (e.g., $\mathrm{b}_{4 \alpha} \mathrm{y}_{7 \beta}$ ). Lysine immonium ions, which maintain the crosslink to the other peptide, are labeled as $\mathrm{K}^{\mathrm{L} \alpha}$, where $\mathrm{L}$ represents the crosslinker molecules (e.g., DSS or DST) and $\alpha$ is the other peptide. Due to the repeating alanine sequences of the 

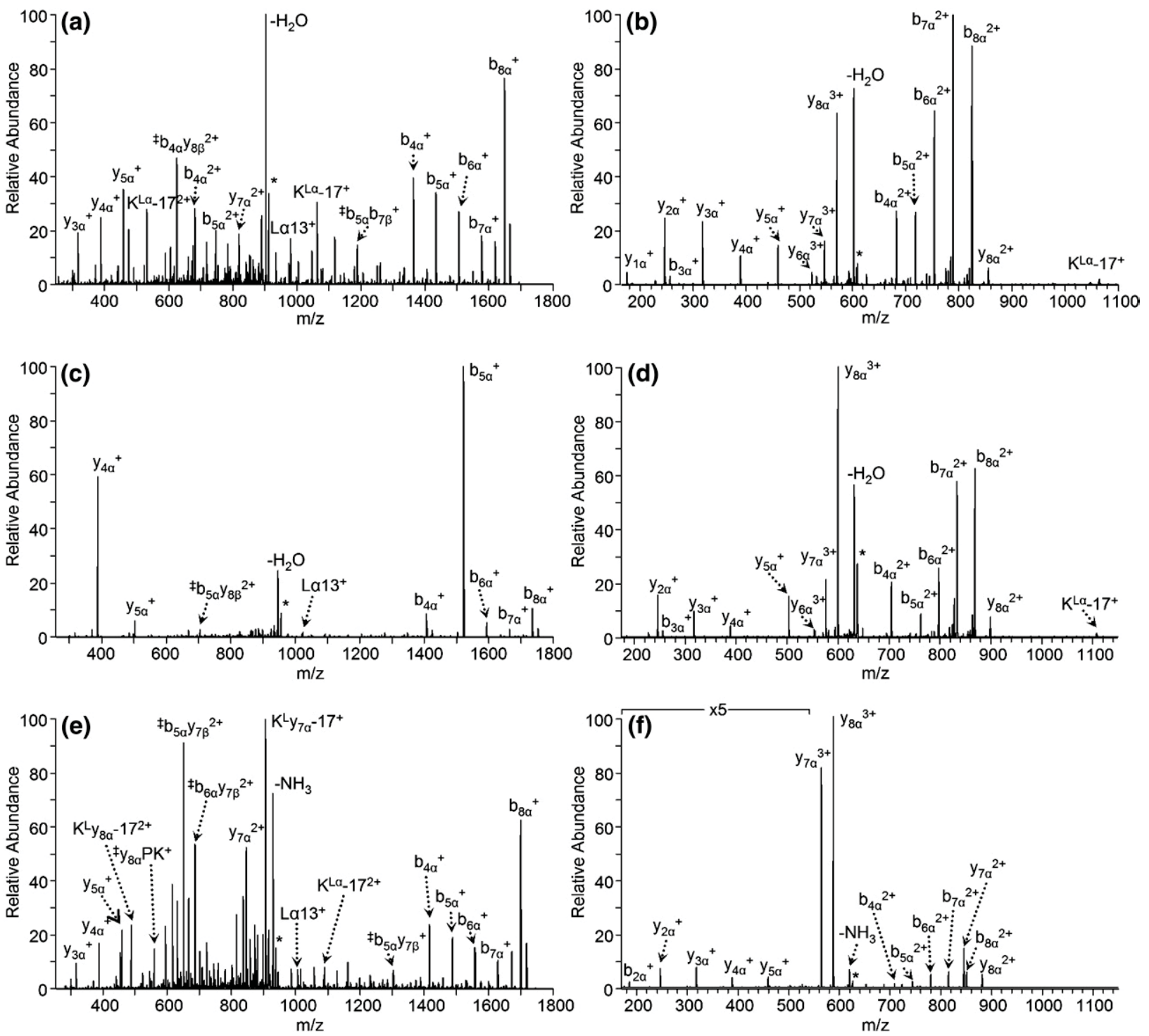

Figure 1. CAD spectra of DSS intermolecularly crosslinked peptides. Precursor ions were (a) [AKA $+\mathbf{A K A}+\mathrm{DSS}+2 \mathrm{H}]^{2+},(\mathbf{b})[\mathbf{A K A}+\mathbf{A K A}+\mathrm{DSS}+3 \mathrm{H}]^{3+},(\mathbf{c})[\mathrm{AKD}+\mathbf{A K D}+\mathrm{DSS}+2 \mathrm{H}]^{2+},(\mathbf{d})$ $[\text { AKD }+ \text { AKD }+ \text { DSS }+3 \text { H }]^{3+},(\mathbf{e})[\text { PKA }+ \text { PKA }+ \text { DSS }+2 \mathrm{H}]^{2+}$, and (f) $[$ PKA + PKA + DSS + $3 \mathrm{H}]^{3+}$. An asterisk is used to signify the precursor ion. Several double cleavage product ions could not be uniquely identified due to isobars inherent to the peptide sequences and are labeled with one possible identity preceded by a double dagger symbol.

peptides studied, certain fragment ions cannot be specifically identified as either cleavage of the $\alpha$ peptide or the $\beta$ peptide as the products are isobars, and are labeled with subscript $\alpha / \beta$ to represent such cases.

\section{Dissociation of DSS-Crosslinked Peptides}

Representative CAD spectra of the homo-intermolecularly DSS-crosslinked peptides are shown in Figure 1. For the control crosslinked peptide, [Ac-AAAKAAAAR + DSS + Ac-AAAKAAAAR $+2 \mathrm{H}]^{2+}$, a series of singly-charged non-crosslinked y-ions were observed in increasing abundance as the site of cleavage moves closer to the crosslinked lysine residue (i.e., $\mathrm{y}_{5 \alpha}>\mathrm{y}_{4 \alpha}>$ $\left.\mathrm{y}_{3 \varkappa}\right)$ (Figure 1a). Similar to this y-ion series, the abun- dances of singly-charged crosslinked b-ions increased as the amide bond cleavage site moved towards K4, with the exception of the $b_{8 c}$ fragment ion, which was observed as the most abundant b-ion. Without the mobile proton several double cleavage products, such as $b_{4 \alpha} y_{8 \beta}$ and $b_{5 \alpha} b_{7 \beta}$, were also formed at similar abundances to the single cleavage fragment ions. Crosslinked lysine immonium ions were detected after the loss of neutral ammonia, as had previously been observed by Gaucher et al. [23], and cleavage of the crosslink amide also occurred, yielding the $\mathrm{L} \alpha 13$ ion of $\mathrm{m} / \mathrm{z}$ 980.5. Dissociation of the triply-charged species yielded a more easily interpretable product ion spectrum in which greater than $95 \%$ of the fragment ions were single cleavage b- and y-type ions (Figure 1b). A 
full series of $y$-ions and b-ions were observed, both modified $\left(\mathrm{y}_{6 \alpha}-\mathrm{y}_{8 \alpha}\right.$ and $\left.\mathrm{b}_{4 \alpha}-\mathrm{b}_{8 \alpha}\right)$ and noncrosslinked $\left(\mathrm{y}_{1 \alpha}-\mathrm{y}_{5 \alpha}\right.$ and $\left.\mathrm{b}_{2 \alpha}-\mathrm{b}_{3 \alpha}\right)$, but the relative abundances of these fragment ions did not follow any strict trend. Triply-charged crosslinked y-ions were observed and the crosslinked b-ions were also detected in the higher, $2+$, charge state compared with the dissociation of the analogous doubly-charged precursor ions. In general, for both the $b$ - and y-ions, as the cleavage site moved further away from the crosslink, the fragment ion abundance increased. At a much lower abundance, the $\mathrm{K}^{\mathrm{L} \alpha}-17$ product ion was also detected.

CAD of the homo-intermolecularly DSS-crosslinked Ac-AAAKDAAAR peptide yielded very few sequence ions for the doubly-protonated precursor ion, as shown in Figure 1c. With both protons sequestered on the C-terminal arginine residues, aspartic acid directed fragmentation dominates and the two products of cleavage C-terminal to D5 are observed at a high abundance $-y_{4 \alpha}$ and $b_{5 \alpha}$. The other three crosslinked b-ions were also detected, but at a much lower abundance. Only one other y-ion is observed in the product ion spectrum. Cleavage $\mathrm{N}$-terminally to the aspartic acid residue yielded the product ions $\mathrm{y}_{5 \alpha}$ and $\mathrm{b}_{4 \alpha}$, but at a much lower abundance. The triply-charged precursor ion possesses a mobile proton, and dissociation of this species was not dominated by a single pathway; rather, a full series of $b$ - and $y$-ions were seen limited only by the low-mass cut-off inherent to resonant excitation in ion traps (Figure 1d). Unlike the CAD spectrum for the Ac-AAAKAAAAR crosslinked peptide, no distinct trends were observed regarding fragment ion abundances. Upon CAD, the crosslinked [Ac-AAPKAAAAR + DSS + Ac-AAPKAAAAR $+2 \mathrm{H}]^{2+}$ peptide yielded an abundance of double cleavage products as evident in Figure 1e. Cleavage of the amide bond N-terminal to the proline residue, $\mathrm{P} 3$, dominated the dissociation of this ion producing crosslinked internal ions ( $\left.\mathrm{y}_{7 \alpha} \mathrm{PKA}\right)$, lysine immonium ions linked to the $\mathrm{y}_{7 \alpha}$ ion $\left(\mathrm{K}^{\mathrm{L}} \mathrm{y}_{7 \alpha}-\right.$ 17), and a series of $b_{n \alpha} y_{7 \beta}$ fragment ions. Most of these fragment ions are redundant as they do not provide additional information to identify the location of the crosslink nor sequence the constituent peptides. Dissociation of the triply-charged species was similarly dominated by cleavage $\mathrm{N}$-terminal to the proline residue yielding the $\mathrm{y}_{7 \alpha}$ fragment; in addition a high abundance of the $\mathrm{y}_{8 u}$ product was observed as shown in Figure 1f. No cleavage between P3 and K4 was detected for the DSS crosslinked Ac-AAPKAAAAR, regardless of precursor ion charge state.

The hetero-crosslinked peptides containing one proline and a single aspartic acid residue exhibited dissociation that followed both Asp- and Pro-directed pathways. CAD mass spectra of these doubly-charged DSS-crosslinked species were typically dominated by fragmentation Cterminal to the aspartic acid residue and to a lesser degree, $\mathrm{N}$-terminal to the proline. A representative CAD spectrum is shown in Supplemental Figure 1a (which can be found in the electronic version of this article) for [Ac-AAAK-
$\mathrm{PAAAR}+\mathrm{DSS}+$ Ac-AADKAAAAR $+2 \mathrm{H}]^{2+}$. Cleavage of the amide bond between $\mathrm{D} 3$ and $\mathrm{K} 4$ of the $\beta$ peptide (Ac-AADKAAAAR), thus resulting in the $y_{6 \beta}^{2+}$ ion, was the most abundant pathway and the two proline-directed fragments were the next two most abundant ions, $\mathrm{y}_{5 x}^{2+}$ and $\mathrm{b}_{4 \omega^{*}}^{+}$. Also present, but to a much lesser degree, were the other crosslinked b-ions as well as a lysine immonium fragment crosslinked to Ac-AADKAAAAR. It should be noted that due to the alanine sequences present in both peptides which create isobaric species, certain fragment ions could not be identified conclusively as to whether the bond cleavage occurred within the $\alpha$ or the $\beta$ peptide (e.g., $b_{5 \alpha}$ has the same mass as the $b_{5 \beta}$ fragment and as such is labeled as $b_{5 \alpha / \beta}$ in Supplemental Figure S1a). Dissociation of the triply-charged DSS crosslinked peptide resulted in an almost complete series of b- and y-type fragment ions, as evident in Supplemental Figure S1a. With the addition of the mobile proton, dissociation of the $\beta$ peptide $C$ terminal to the Asp residue did not dominate the spectrum, and was in fact one of few sequence fragment ions not observed. Proline-directed fragmentation still yielded two of the most abundant product ions, $\mathrm{b}_{4 x}^{2+}$ and $\mathrm{y}_{5 \mathrm{x}}^{2+}$. This data suggests that to obtain fragmentation information essential to locate the site of crosslinking as well as to sequence the two linked peptides, dissociation of more highly-charged crosslinked peptides would be beneficial.

\section{Dissociation of DST-Crosslinked Peptides}

The DST-crosslinked peptides exhibited similar dissociation pathways as the DSS-linked species, as shown in Figure 2, with one notable exception in that cleavage of the C7-C8 bond of the DST crosslinker was observed for the doubly-charged precursor ions (described later in this section). The doubly-charged DST homo-intermolecularly crosslinked Ac-AADKAAAAR peptide predominantly dissociated via Asp-directed fragmentation, C-terminal to D3, as seen in Figure 2a, yielding the $\mathrm{y}_{6 \alpha}^{2+}$ ion. At much lower abundances, double cleavage products, including ones involving cleavage C-terminal to the aspartic residues of both peptides $\left(\mathrm{y}_{6 \alpha} \mathrm{y}_{6 \beta}\right)$ and crosslinked b-ions were observed. CAD of the triplycharged species, presumed to have a mobile proton, yielded a full series of $b$ - and y-type fragment ions, again only limited by the low-mass cut-off (Figure 2b). With the mobile proton, the Asp-directed fragmentation which dominated the CAD mass spectrum of the doubly-charged crosslinked peptide was circumvented. Fragment ions unique to crosslinked peptides, including products from the dissociation of the crosslink amide bond ( $\mathrm{L} \alpha 9$ and $\mathrm{L} \alpha 5)$, and crosslinked lysine immonium ions $\left(K^{\mathrm{L} \alpha}\right.$ and $\mathrm{K}^{\mathrm{L} \alpha}$-17) were also detected. For all of the DST-crosslinked peptides analyzed, fragmentation of the C7-C8 bond of the DST crosslinker occurred, as illustrated in Scheme 2. Dissociation of this bond yields product ions corresponding to +56 and $+58 \mathrm{Da}$ adducts of the unmodified peptides, and they are labeled as $L \alpha 7$ and $L \beta 7$ ions. (It should be noted that there is a $1 \mathrm{~m} / \mathrm{z}$ unit difference between the precursor 

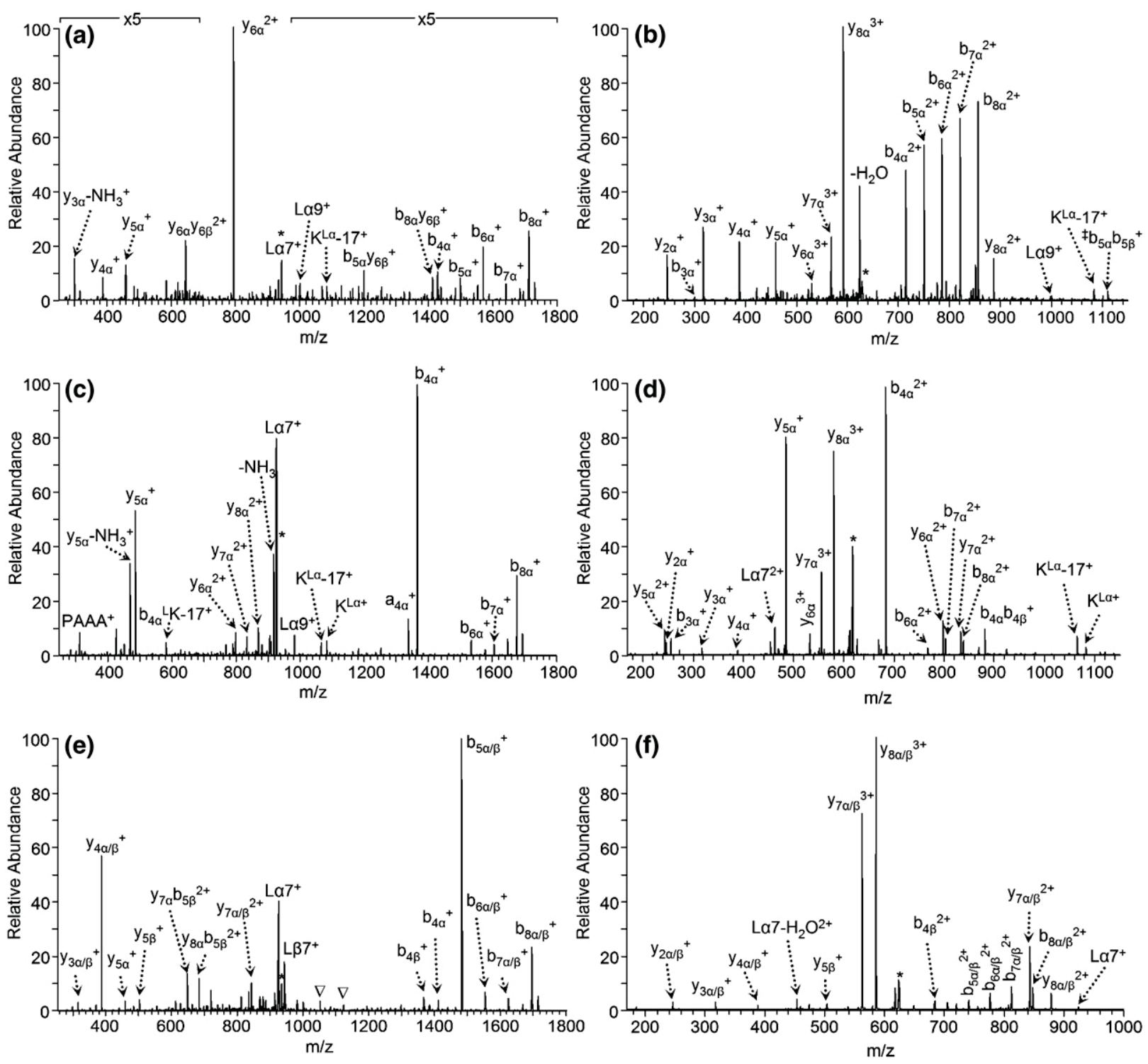

Figure 2. CAD spectra of DST intermolecularly crosslinked peptides. Precursor ions were (a) [DKA + DKA + DST $+2 \mathrm{H}]^{2+},(\mathbf{b})[\mathrm{DKA}+\mathrm{DKA}+\mathrm{DST}+3 \mathrm{H}]^{3+},(\mathbf{c})[\mathrm{AKP}+\mathbf{A K P}+\mathrm{DST}+2 \mathrm{H}]^{2+},(\mathbf{d})$ $[\mathrm{AKP}+\mathrm{AKP}+\mathrm{DST}+3 \mathrm{H}]^{3+},(\mathbf{e})[\mathbf{P K A}+\mathbf{A K D}+\mathrm{DST}+2 \mathrm{H}]^{2+}$, and $(\mathbf{f})[\mathbf{P K A}+\mathbf{A K D}+\mathrm{DST}+$ $3 \mathrm{H}]^{3+}$. The first peptide listed is referred to as the $\alpha$ peptide and the second peptide as $\beta ; \alpha / \beta$ nomenclature is used to signify that cleavage could have occurred on either peptide. Internal ions that could not be conclusively identified due to isobaric species are labeled with inverted triangle symbols.

An asterisk is used to signify the precursor ion.

ion and $\mathrm{L} \alpha 7$ fragment ions in Figure 2a-d.) For the second proline-containing peptide analyzed in this study, Ac-AAAKPAAAR, dissociation of the doublycharged DST-crosslinked peptide predominantly produced three fragment ions, $\mathrm{L} \alpha 7$ and the two fragments corresponding to proline directed dissociation, $\mathrm{y}_{5 \kappa}$ and $\mathrm{b}_{4 \alpha}$ (Figure 2c). The triply-charged Ac-AAAKPAAAAR + DST + Ac-AAAKPAAAR ion also showed preferential cleavage between $\mathrm{K} 4$ and $\mathrm{P} 5$, while the other b- and $y$-type ions had abundances similar to that observed for the $2+$ charged precursor (Figure 2d). Regardless of the charge state, proline-directed fragmentation dominated the CAD spectrum of the Ac-AAAKPAAAR crosslinked peptides.
Collisionally activated dissociation of [Ac-AAP$\mathrm{KAAAAR}+\mathrm{DST}+\mathrm{Ac}-\mathrm{AAAKDAAAR}+2 \mathrm{H}]^{2+}$ more clearly shows fragmentation of the C7-C8 bond of DST, producing the corresponding $\mathrm{L} \alpha 7$ and $\mathrm{L} \beta 7$ ions, as shown in Figure 2e. Aspartic acid-directed fragmentation dominated the product ion spectrum yielding $\mathrm{y}_{4 \alpha / \beta}^{+}$ and $b_{5 \alpha / \beta}^{+}$, and numerous proline-directed fragments were detected between $\mathrm{m} / \mathrm{z} 600$ and 1300, including internal ions of the form $\mathrm{PKA}_{\mathrm{n}}$ crosslinked to $\mathrm{b}_{\mathrm{n} \beta}$ ions (labeled with an inverted triangle symbol) and $\mathrm{y}_{7 \alpha}$ containing fragments. The influences of both Asp and Pro were observed by the formation of certain product ions, including $\mathrm{y}_{7 \mathrm{\alpha}} \mathrm{b}_{5 \beta}^{2+}$, analogous to those observed for the DSS-crosslinked species. The triply-charged DST 


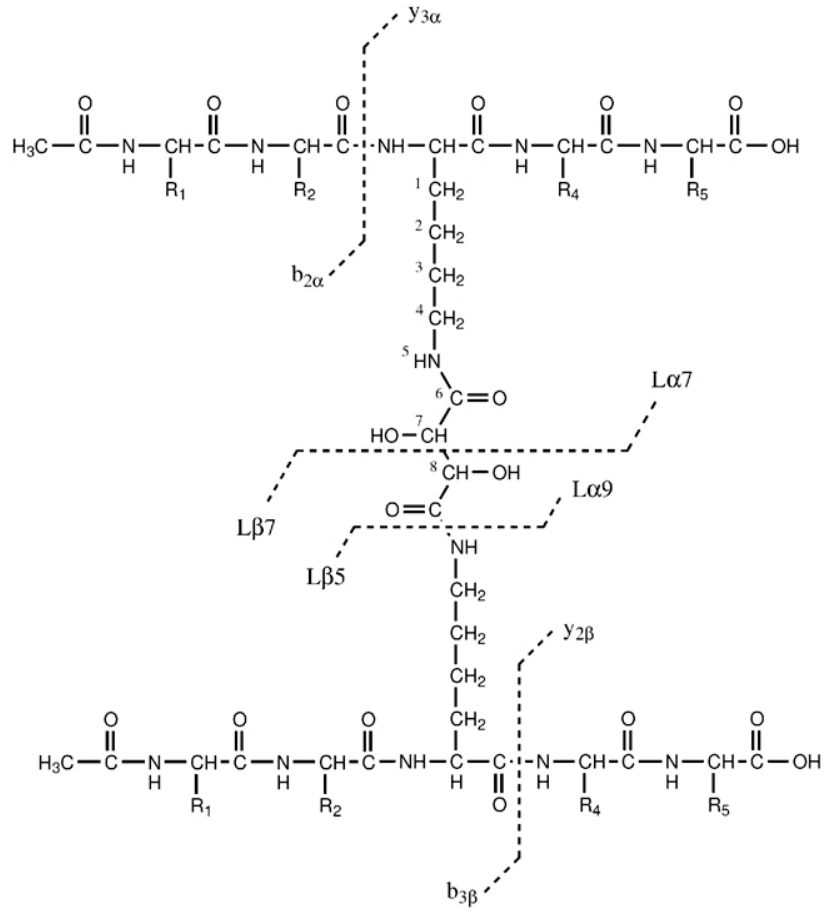

Scheme 2

hetero-crosslinked peptide yielded a series of doublycharged crosslinked b-ions, a series of crosslinked $y$ ions, and a series of uncrosslinked y-ions for both peptides, as evident in Figure $2 \mathrm{f}$. The aspartic acid effects were not observed when the precursor ion had a mobile proton, but fragment ions with N-terminal prolines were detected at high abundances, in particular $\mathrm{y}_{7 \alpha / \beta}$. The DST specific cleavage of the C7-C8 bond was also observed, but at lower abundances compared to that observed for the analogous doubly-charged precursor ion. Dissociation of the amide bond N-terminal to the crosslinked lysine for either constituent peptide, Ac-AAPKAAAAR or Ac-AAAKDAAAR, to yield the expected $\mathrm{y}_{6 \alpha}$ or $\mathrm{y}_{6 \beta}$ fragments did not occur, suggesting a cleavage bias due to the crosslink.

\section{Fragment Ion Type Abundances}

The relative abundance of each fragment ion type was calculated to shed light on the general trends of the dissociation of these proline- and aspartic acid-containing crosslinked peptides. As shown in Figure 3a for the doubly-charged DSS-crosslinked peptides, a-, b-, and $\mathrm{y}$-type fragment ions, on average, accounted for $\sim 75 \%$ of the total product ion abundance. For aspartic acidcontaining crosslinked peptides, this abundance increased to over $85 \%$ as Asp-directed fragmentation of these doubly-charged precursor ions, in which both protons are sequestered, produced predominantly single cleavage $\mathrm{b}$ - and $\mathrm{y}$-type ions. Multiple cleavage fragments, including internal ions, $b / b, b / y, y / y$, and linked lysine immonium ions, accounted for $19 \%$ of all the fragment ions. For the doubly-charged DSS- crosslinked peptides, two types of fragment ions unique to crosslinked peptides, those involving cleavage of the crosslink amide bond and crosslinked lysine immonium ions, accounted for $2.5 \%$ and $\sim 6 \%$ of the product ion abundance, respectively. Crosslinked peptides containing Ac-AAPKAAAAR yielded a high abundance of internal ions; $\sim 11 \%$ of all the fragments observed were internal ions, compared to $2 \%$ for the non-Ac-AAPKAAAAR crosslinked peptides. A majority of these internal ions had the proline residue at the N-terminus. Dissociation of the various triply-charged DSS-linked peptides, all of which possess a mobile proton, yielded a much higher abundance of single-cleavage a-, b-, and y-type fragment ions-on average greater than 95\% relative abundance, as shown in Figure $3 \mathrm{~b}$. The total abundance of the crosslinked lysine immonium ions was less than $1 \%$, and cleavage of the crosslink amide bond was observed at less than $0.1 \%$ abundance. For the triply-charged aspartic acid- or the proline-containing crosslinked peptides, there were no major differences in fragment ion abundances except that $y$-ions were observed at over $76 \%$ relative abundance for the AcAAPKAAAAR crosslinked species, due to preferential cleavage $\mathrm{N}$-terminal to the proline residue yielding an unusually high abundance of $\mathrm{y}_{7 \alpha}$ fragments. No significant differences in the multiple cleavage products were detected between the various crosslinked peptides.

The DST-crosslinked peptides, particularly for species without a mobile proton as noted earlier, exhibited far more unique dissociation pathways compared to the DSS-linked peptides. Fragmentation of the C7-C8 bond of the DST crosslinker occurred for all of these crosslinked peptides in the $2+$ charge state, accounting for over $21 \%$ of the total fragment ion abundance, as shown in Figure 4a, and these fragments do not provide any diagnostic information for determining the crosslink location or sequencing the peptide. Similar to the DSS-crosslinked peptides, doubly-charged DSTlinked species yielded on average $60 \%$ single cleavage $a-, b-$, and y-ions, with the remainder accounted for by multiple cleavage products and crosslinker specific product ions. The latter product ions, excluding ones stemming from dissociation of the DST linker at the C7-C8 bond, were observed at $\sim 15 \%$ relative abundance, similar to that for the DSS-crosslinked species. Various internal ions were also observed at similar abundances for the DST-linked peptides than for the DSS-crosslinked products, 3\% relative abundance compared to $\sim 5 \%$, respectively. The DST-crosslinked products containing the Ac-AAPKAAAAR peptide did exhibit a higher degree of internal ion formation than the other peptides studied, but the difference was not as pronounced as that for the DSS-crosslinked products. Dissociation of the triply-charged DST-crosslinked peptides, as summarized in Figure $4 b$, yielded similar results as the analogous DSS-linked species. Across the series, over $92 \%$ of the fragment ion abundance consisted of single bond cleavage $a-, b_{-}$, and y-ions. Fragment ions due to cleavage of the DST crosslinker at the 

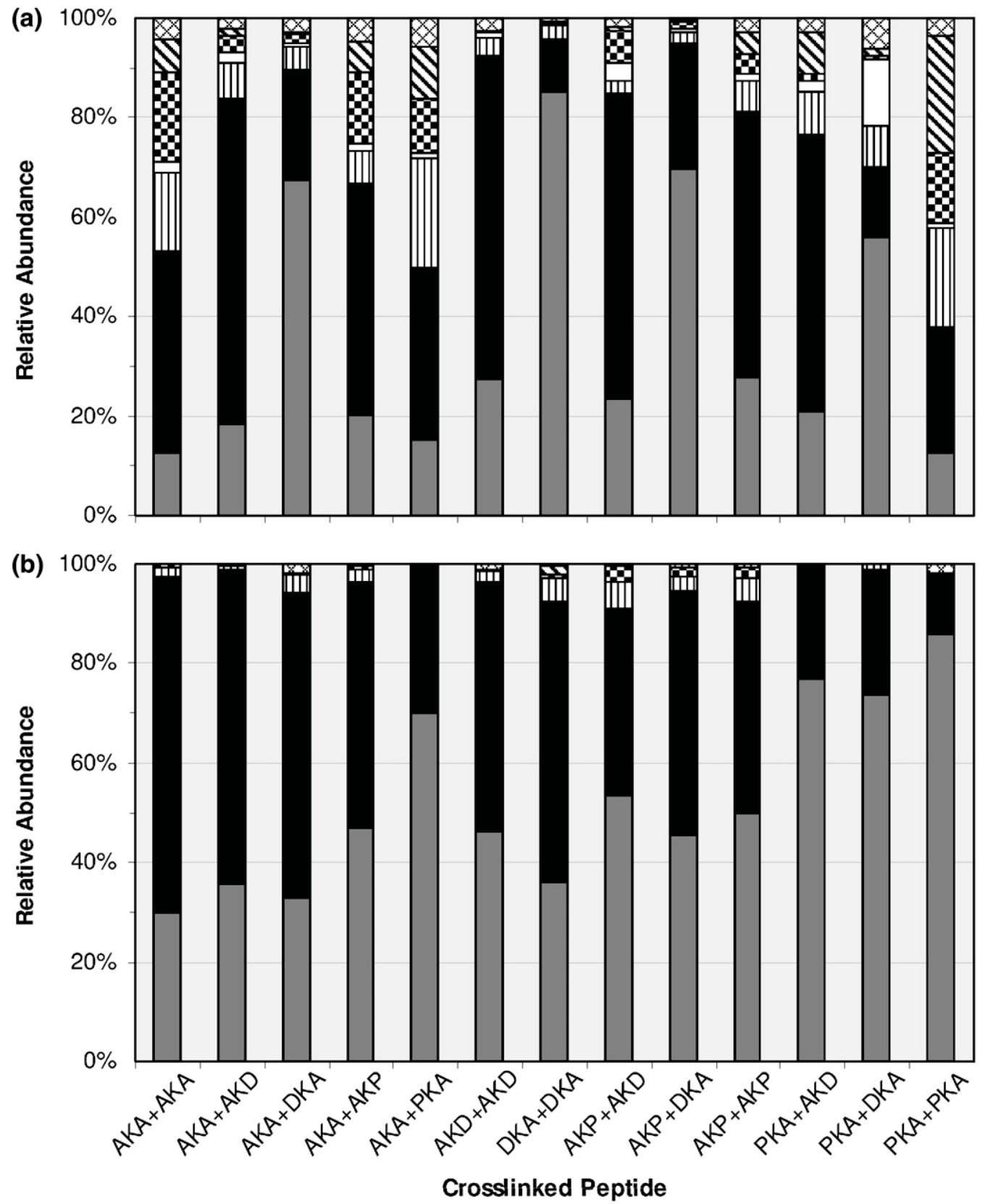

\begin{tabular}{|c|c|c|}
\hline $\begin{array}{l}\square \mathrm{y} \text {-ions } \\
\square \mathrm{K} \text { Immonium }\end{array}$ & $\begin{array}{l}\text { b- and a-ions } \\
\text { v Internal lons }\end{array}$ & $\begin{array}{l}\square \mathrm{b} / \mathrm{b}+\mathrm{b} / \mathrm{y}+\mathrm{y} / \mathrm{y} \quad \square \text { Crosslink Amide } \\
\text { Unidentified }\end{array}$ \\
\hline
\end{tabular}

Figure 3. Relative fragment ion abundance for the DSS crosslinked peptides in the (a) $2+$ charge state and (b) $3+$ charge state. Each category represents the abundance of that product ion type relative to the total fragment ion abundance minus neutral losses from the precursor ion. Errors are less than $0.5 \%$ relative abundance.

C7-C8 bond totaled less than $1 \%$ relative abundance, suggesting that this fragmentation pathway is preferred only for precursor ions without a mobile proton. The only modest difference between the fragmentation patterns of the triply-charged DSS- and DST-linked peptides was an increased abundance of double cleavage products and crosslinked lysine immonium ions, from $3 \%$ to $6 \%$.
The addition of the mobile proton to these DSSand DST-crosslinked peptides increased the abundance of useful sequence ions, ones which are easily interpretable. Also, aspartic acid-directed fragmentation of the triply-charged ions did not occur, thus yielding a wider array of single cleavage products. Proline-directed fragmentation still dominated the CAD spectra of the triply-charged crosslinked pep- 

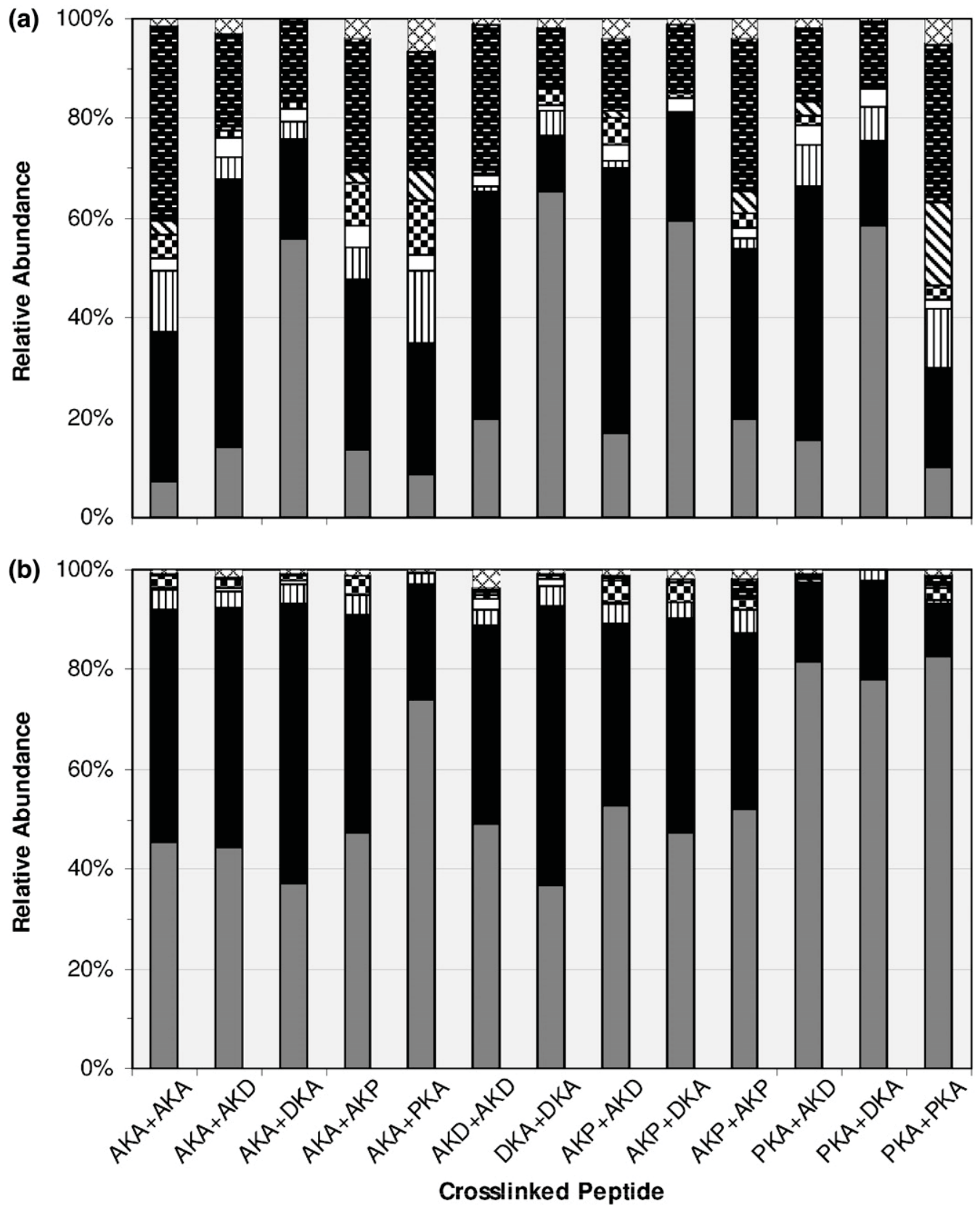

\begin{tabular}{|c|c|c|c|}
\hline $\begin{array}{l}\text { 口y-ions } \\
\text { a K Immonium }\end{array}$ & $\begin{array}{l}\text { b- and a-ions } \\
\mathbf{v} \text { Internal lons }\end{array}$ & $\begin{array}{l}\square \mathrm{b} / \mathrm{b}+\mathrm{b} / \mathrm{y}+\mathrm{y} / \mathrm{y} \\
\mathrm{DST} \text { Cleavages }\end{array}$ & $\begin{array}{l}\text { Crosslink Amide } \\
\text { Unidentified }\end{array}$ \\
\hline
\end{tabular}

Figure 4. Relative fragment ion abundance for the DST crosslinked peptides in the (a) $2+$ charge state and (b) $3+$ charge state. Each category represents the abundance of that product ion type relative to the total fragment ion abundance minus neutral losses from the precursor ion. Errors are less than $0.5 \%$ relative abundance.

tides, however, a full series of b- and y-ions were still observed, with the exception of cleavage C-terminal to proline residues. The degree of multiple-cleavage products, particularly the abundance of internal ions for the proline containing peptides, was greatly reduced for dissociation of the more highly-charged crosslinked peptide ions.
Effect of Crosslinkers on Cleavage Bias Adjacent to the Modified Lysine

As evident from the dissociation of the intermolecularly crosslinked peptides, the aspartic acid or proline residue tends to direct peptide fragmentation. One earlier study indicated a qualitative enhancement of cleavage of the 

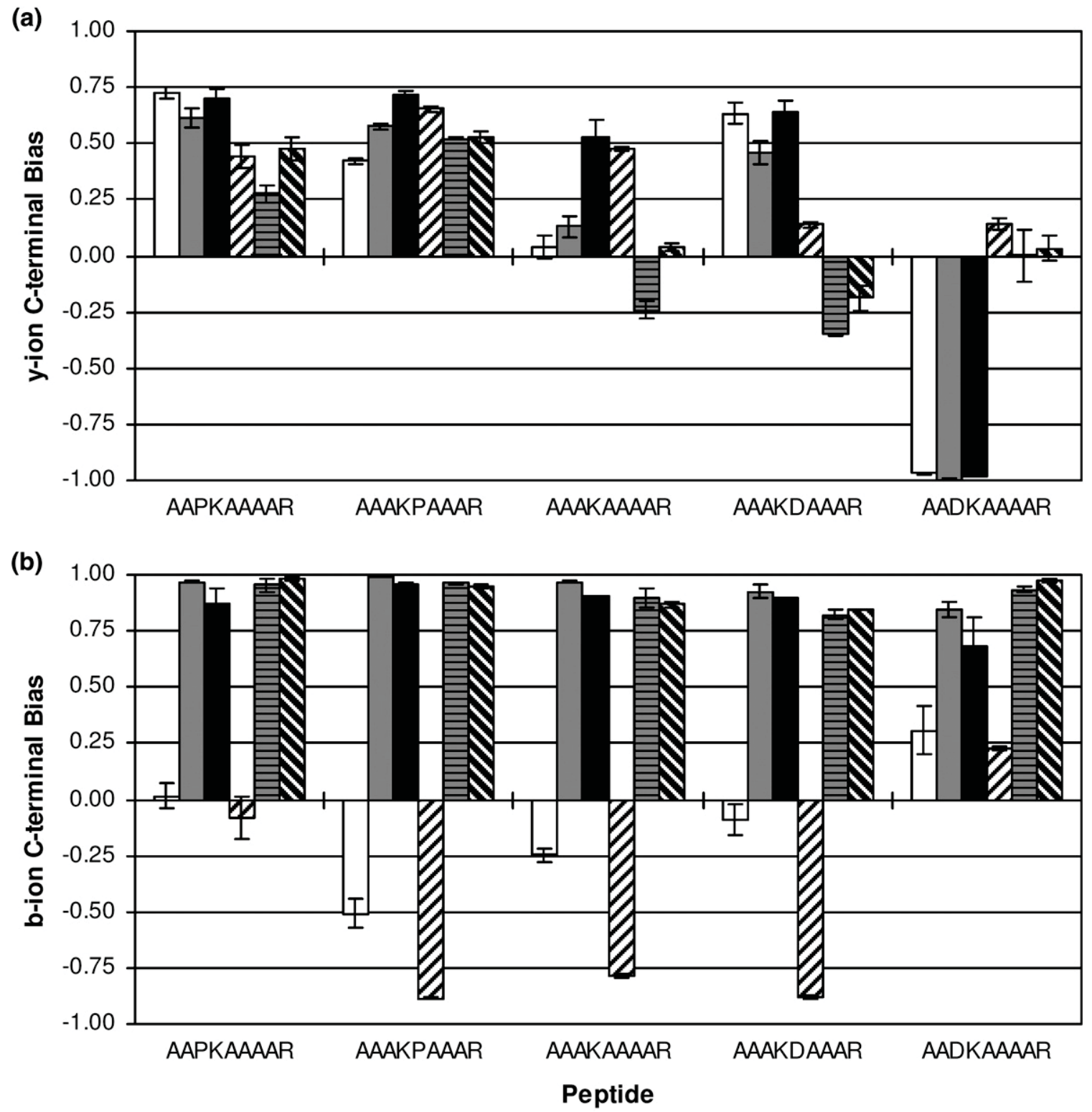

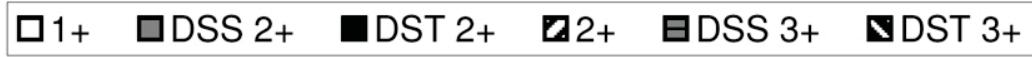

Figure 5. The C-terminal cleavage bias relative to the lysine residue, for both the unmodified peptides in the $1+$ and $2+$ charge state and the homo-intermolecularly crosslinked peptides in the $2+$ and $3+$ charge state, for $(\mathbf{a}) \mathrm{y}$-ions and (b) b-ions.

amide bond adjacent to the crosslinked lysine for intramolecularly crosslinked peptides, so we aimed to investigate a possible preference for intermolecularly crosslinked species [23]. The directionality bias of cleavage to the crosslinked lysine was determined for both the unmodified peptides $(1+$ and $2+)$ and the homo-intermolecularly crosslinked peptides $(2+$ and $3+)$ as shown in Figure 5. A positive C-terminal cleavage bias value indicates that more fragment ions were formed from cleavage of the amide bond C-terminal to the crosslinked lysine, whereas a negative value indicates a bias towards forming product ions from dissociation of the N-terminal amide bond. For species without a mobile proton (e.g., 1+ charge state for unmodified peptides, $2+$ charge state for crosslinked peptides), the influences of proline and aspartic acid on $\mathrm{y}$-ion formation were not greatly affected upon crosslinking (Figure 5a). The y-ion C-terminal bias was only enhanced for the Ac-AAAKPAAAR and Ac-AAAKAAAAR peptides after crosslinking. All of the doubly-charged crosslinked peptides preferentially dissociated via cleavage of the C-terminal amide bond to the lysine residue, except for the homo-intermolecularly crosslinked AcAADKAAAAR peptide; these species fragmented via Asp-direction dissociation C-terminal to D3, or N-terminally to the modified lysine residue. With the addition of a mobile proton, the Asp-containing crosslinked peptides 
did not exhibit any significant cleavage bias towards the formation of $y$-ions. The crosslinked peptides with proline residues still displayed signs of a C-terminal fragmentation bias in the $3+$ charge state; however, these results can be explained by preferential cleavage $\mathrm{N}$-terminally to proline residues. With the proline residue positioned N-terminally to the lysine (e.g., Ac-AAPKAAAAR), cleavage of the bond between P3 and K4 is suppressed, thus decreasing the $\mathrm{y}_{6 \alpha}$ product ion abundance relative to $\mathrm{y}_{5 \alpha}$ fragment ions. For the other proline containing peptide, Ac-AAAKPAAAR, formation of the $\mathrm{y}_{5 \alpha}$ ion is enhanced relative to $\mathrm{y}_{6 \alpha}$ due to Pro-directed dissociation between $\mathrm{K} 4$ and P5.

Analysis of the b-ions detected showed that the unmodified peptides all preferentially dissociated N-terminally to $K 4$ yielding $b_{3}$ ions, as shown in Figure $5 b$, except for [Ac-AADKAAAAR $+\mathrm{H}^{+}$, in which no $b_{3}$ or $b_{4}$ ions were detected (i.e., peak abundance was below the peak threshold). For the doubly-charged unmodified peptides, the N-terminal cleavage bias increased over the singlycharged peptides, with the Ac-AADKAAAAR peptide as the lone exception. This particular unmodified peptide exhibited similar cleavage biases for both $b$ - and $y$-ions. Interestingly, analysis of the b-ions suggests there is a significant C-terminal cleavage bias for all of the crosslinked peptides. The doubly-charged crosslinked peptides have both protons localized on the C-terminal arginines, so one would not expect to detect $b_{3}$ ions, which do not contain the crosslink or a charge. Cleavage $\mathrm{C}$ terminal to the lysine residue yields $\mathrm{a}_{4 x}$ ion, which contains the crosslinker as well as the $\beta$ peptide with the sequestered proton at its C-terminal arginine. A high C-terminal cleavage bias for the formation of b-ions also was observed for all of the triply-charged crosslinked peptides. Even with the additional mobile proton, $b_{3 x}$ ions were not detected at high abundances in the CAD spectra. Having a proline residue $\mathrm{N}$-terminal to the lysine reduces the abundance of $\mathrm{N}$-terminal fragment ions (e.g., $b_{3}$ ), while a proline C-terminal enhances the formation of $b_{4}$ ions. In the $3+$ charge state, the aspartic acid effect does not dominate the peptide fragmentation pathways, and any cleavage bias due to the aspartic acid residues is eliminated. However, the high $\mathrm{C}$ terminal $b$-ion abundance relative to $\mathrm{N}$-terminal fragments for the Asp-containing crosslinked peptides, as well as the Ac-AAAKAAAAR peptide, suggests that the presence of the crosslink affects the dissociation of the amide bonds adjacent to the modified lysine.

The observed C-terminal cleavage bias could be due to the composition and position of the amino acids residues chosen for this study. Cleavage C-terminal to the crosslinked lysine yields the $\mathrm{y}_{5 \alpha}$ fragment ion (XAAAR) and $a b_{4 \alpha}$ fragment ion (Ac-AAXK + crosslinker $+\beta$ peptide), while $\mathrm{N}$-terminal cleavage produces the $b_{3 \alpha}$ fragment (Ac-AAX) and the corresponding $\mathrm{y}_{6 \alpha}$ fragment (KXAAAR + crosslinker $+\beta$ peptide). The $b_{3}$ fragment is unlikely to carry a charge without a basic residue present and thus would not be observed. The $b_{4 x^{\prime}} \mathrm{y}_{6 \alpha^{\prime}}$ and $\mathrm{y}_{5 \alpha}$ fragments would all be detected as ions due to the presence of at least one C-terminal arginine residue. The location of the arginines may explain the greater Cterminal cleavage bias observed for the b-ions compared to $y$-ion formation, particularly for the triply-charged precursor ions without a proline residue. However, in most protein crosslinking experiments, crosslinked peptides with C-terminal arginines will be produced after enzymatic digestions with trypsin, and the trends observed in this study should be considered in sequence identification software.

For the unmodified peptides, the mobile proton is assumed to be located on the second most basic site, the $\varepsilon$-amine group of the lysine residue. This proton, when mobilized upon ion activation, could easily promote charge-directed fragmentation at either amide bond adjacent to the lysine residue. However, after the crosslinking reaction which produces an amide bond involving the amino group of the lysine side chain, the third proton of the crosslinked peptide is likely not as localized as that of the mobile proton for the unmodified peptides. Ongoing work in our lab examining infrared multiphoton dissociation of crosslinked peptides has shown enhanced photodissociation efficiencies for the triply-charged crosslinked peptides compared to the doubly-charged unmodified peptides, suggesting a lower activation energy for the less basic crosslinked species. The gas-phase basicity differences and probable localization of protons between crosslinked and non-crosslinked peptides may help explain this enhanced C-terminal cleavage bias to the linked lysine residues.

\section{Dissociation of Other Crosslinked Peptides}

The peptides $\alpha$-MSH (Ac-SYSMEHFRWGKPV-NH ${ }_{2}, \alpha$ peptide) and neurotensin (Pyr-LYENKPRRPYIL, $\beta$ peptide) were crosslinked by either DSS or DST to determine whether the same dissociation trends are observed for crosslinked peptides with more random sequences. Since the two crosslinkers react with primary amines, it was assumed that the crosslink was formed between $\mathrm{K} 11$ of $\alpha$-MSH and $\mathrm{K} 6$ of neurotensin, and the product ion spectra of the DST- crosslinked species support this assumption (Figure 6). Dissociation of the triply-charged precursor ion was dominated by cleavage C-terminal to the acidic residues, E5 of $\alpha$-MSH and $\mathrm{E} 4$ of neurotensin, yielding $\mathrm{y}_{8 \alpha}^{3+}\left(\mathrm{m} / \mathrm{z}\right.$ 937.8) and $\mathrm{y}_{9 \beta}^{3+}$ $(\mathrm{m} / z$ 978.7) as the three protons are localized by the three total arginine residues present in the two peptides (Figure 6a). To a lesser degree proline-directed cleavages were observed, producing $b_{11 \alpha}^{3+}(m / z$ 1080.0) and $\mathbf{b}_{9 \beta}^{3+}(\mathrm{m} / z$ 982.7) Without a mobile proton, dissociation of the C7-C8 bond of the DST crosslink was observed producing $\mathrm{L} \beta 7^{2+}$ and the corresponding $\mathrm{L} \alpha 7^{+}$product ions of $\mathrm{m} / \mathrm{z} 865.6$ and 1721.9, respectively. Other crosslinker specific fragment ions were detected including cleavage of the crosslink amide bond yielding the unmodified constituent peptides ( $\mathrm{L} \beta 5^{2+}$ and $\left.\mathrm{L} \alpha 5^{+}\right)$, and the constituent peptides modified by the DST 

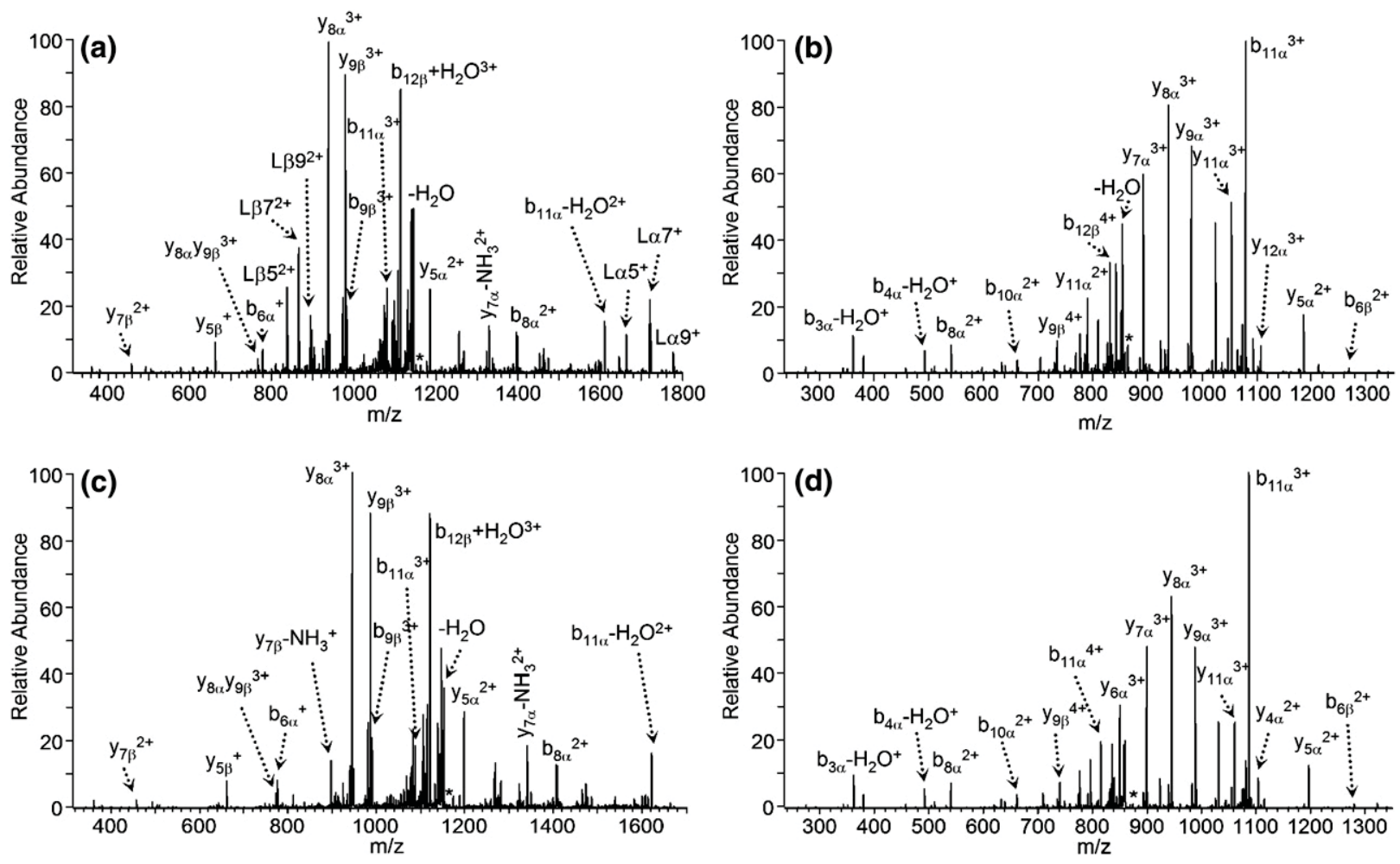

Figure 6. CAD spectra of $\alpha$-MSH crosslinked to neurotensin by DST in the (a) $3+$ charge state and (b) $4+$ charge state. Product ion spectra of $\alpha-\mathrm{MSH}$ crosslinked to neurotensin by DSS in the (c) $3+$ charge state and (d) $4+$ charge state. $\alpha$-MSH (Ac-SYSMEHFRWGKPV-NH ${ }_{2}$ ) is referred to as the $\alpha$ peptide and neurotensin (Pyr-LYENKPRRPYIL) as the $\beta$ peptide; the crosslink is between K11 of $\alpha$-MSH and K6 of neurotensin. An asterisk is used to signify the precursor ion.

crosslinker $\left(\mathrm{L} \beta 9^{2+}\right.$ and $\left.\mathrm{L} \alpha 9^{+}\right)$. Interestingly, crosslinked lysine immonium ions were observed at less than $0.5 \%$ relative abundance for the triply-charged precursor ion, compared to $\sim 5 \%$ for the model crosslinked peptide species without a mobile proton. CAD of the quadruply-charged precursor ion $[\alpha$-MSH + DST + neuroten$\sin +4 \mathrm{H}]^{4+}$ yielded a full series of crosslinked $\mathrm{y}_{\alpha}$ ions $\left(\mathrm{y}_{3 \alpha}-\mathrm{y}_{12 \alpha}\right)$, and a full series of uncrosslinked $\mathrm{b}_{\alpha}$-ions $\left(b_{2 \alpha}-b_{10 \alpha}\right)$, as shown in Figure $6 \mathrm{~b}$. With an additional mobile proton, fragment ions stemming from the cleavage of amide bonds C-terminal to acidic residues were not observed. Proline-directed fragmentation yielded the most abundant product ion $\mathrm{b}_{11 x^{3}}^{3+}$. Similar to the CAD results of the model crosslinked peptides, crosslinker specific product ions were not observed at any significant abundance; instead b- and y-type fragment ions dominated the entire CAD spectrum. Most of the product ions were a result of backbone cleavage along $\alpha-\mathrm{MSH}$, and not neurotensin, with the exception of amino acid specific fragmentation.

The DSS-crosslinked species in the $3+$ charge state produced similar fragment ions as the DST-crosslinked analog (Figure 6c). Ions resulting from cleavage C-terminal to the two glutamic acid residues dominated the CAD spectrum $\left(\mathrm{y}_{8 \alpha}^{3+}\right.$ and $\left.\mathrm{y}_{9 \beta}^{3+}\right)$, and proline-directed products were also abundant $\left(b_{11 \kappa}^{3+}\right.$ and $\left.b_{9 \beta}^{3+}\right)$. Crosslinker specific product ions were not observed for the DSS-crosslinked peptide at similar high abundances as the DSTcrosslinked species without a mobile proton. Such product ions accounted for less than $1 \%$ of the total fragment ion abundance. Collisionally activated dissociation of the quadruply-charged DSS-crosslinked peptide yielded higher sequence coverage, specifically a series of $y$-ions of the $\alpha$-MSH peptide crosslinked to intact neurotensin (Figure $6 \mathrm{~d}$ ). Acidic residue directed cleavages were not observed for the precursor ion possessing a mobile proton; dissociation N-terminal to proline was still dominant yielding the $b_{11 \kappa}$ ions. No crosslinker specific product ions, including crosslinked lysine immonium ions, nor fragments from the cleavage of the crosslink amide bonds were observed for this crosslinked peptide ion.

\section{Conclusions}

Intermolecularly crosslinked peptides, in general, dissociate via similar pathways to that of unmodified peptides. For DSS- and DST-crosslinked peptide ions in which the protons were sequestered, aspartic aciddirected fragmentation dominated the product ion spectra, more so than fragmentation $\mathrm{N}$-terminally to proline residues among the two linked peptides. These doubly-charged crosslinked peptides yielded a high abundance of multiple cleavage products, including $\mathrm{b} / \mathrm{b}, \mathrm{b} / \mathrm{y}, \mathrm{y} / \mathrm{y}$, crosslinked lysine immonium ions, and 
internal ions, which complicated the interpretation of the CAD spectra, but provided complementary sequence information. In particular, for crosslinked peptides with a proline N-terminal to the linked lysine residue (i.e., a PK sequence), a high degree of crosslinked internal ions were formed. The DSTcrosslinked peptide ions without a mobile proton dissociated in a unique manner compared to the analogous DSS species, in which cleavage of the C7-C8 bond of the DST linker molecule was observed regardless of amino acid content.

Dissociation of the crosslinked peptides possessing a mobile proton resulted in almost full sequence coverage (b- and y-type ions) of both peptides, allowing one to determine the site of crosslinking, as cleavage C-terminal to Asp residues was observed to a much lesser degree. Dissociation N-terminal to the proline residues was still prevalent for the more highly-charged crosslinked peptides. Products unique to crosslinked peptides, such as crosslinked lysine immonium ions, multiple cleavage fragments, and cleavage of the crosslinkers, including both the crosslinker amide bond and within the DST linker, accounted for less than $10 \%$ of the fragment ion abundance for the triply-charged species, compared to upwards of $50 \%$ of the fragment ions for precursor ion without a mobile proton. In addition, the crosslinked peptides exhibited a tendency to preferentially cleave C-terminally to the modified lysine residue, particularly in the formation of b-ions, compared to the unmodified peptides. Unless an aspartic acid residue was positioned $\mathrm{N}$-terminally to the crosslinked lysine and the precursor ion did not have a mobile proton, this C-terminal cleavage bias was observed for all of the crosslinked peptides regardless of the position of proline and aspartic acid residues.

By incorporating these dissociation trends noted for crosslinked peptides into computer algorithms, one would expect the confidence in the assignment of product ions and subsequent peptide identification to increase. In the presence of a mobile proton the intermolecularly crosslinked peptide tends to behave as two individual peptides, each modified at the lysine residue by the crosslinker and the other peptide. However, as evident in dissociation of the crosslinked model peptides without a mobile proton, several unique types of fragment ions were identified. Many commercial crosslinkers are primary amine specific, and after crosslinking, in which an amide bond is formed, the overall gas-phase basicity of the peptide or protein is reduced, thus decreasing the ionization efficiency of more highly-charged crosslinked peptides. Particularly for tryptic peptides in which basic residues are not conserved, crosslinked peptides without a mobile proton dissociate via several pathways yielding multiple cleavage product ions (e.g., $b_{\alpha} y_{\beta}$ ), crosslinked lysine immonium ions, and fragments from the dissociation of the crosslink amide bond or of the crosslinker (e.g., $\mathrm{L} \alpha 7$ and L $\beta 7$ fragments of DST crosslinked peptides), as well as the typical b- and y-type product ions. Computer algorithms which do not currently account for these product ion types may lead to incorrect peptide and protein identifications. Also, these crosslinker specific product ion types can provide not only complementary but also confirmatory sequence information which can aid in identifying the location of the chemical crosslink.

\section{Acknowledgments}

The authors gratefully acknowledge funding from the NSF (CHE0718320) and the Welch Foundation (F1155).

\section{References}

1. Heck, A. J. R.; van den Heuvel, R. H. H. Investigation of Intact Protein Complexes by Mass Spectrometry. Mass Spectrom. Rev. 2004, 23(5), 368-389.

2. Juan, H.-F.; Liu, H.-L.; Hsu, J.-P. Recent Developments in Structural Proteomics: From Protein Identifications and Structure Determinations to Protein-Protein Interactions. Curr. Proteom. 2004, 1(3), 183-197.

3. Borch, J.; Jorgensen, T. J. D.; Roepstorff, P. Mass Spectrometric Analysis of Protein Interactions. Curr. Opin. Chem. Biol. 2005, 9(5), 509-516.

4. Sinz, A. Chemical Crosslinking and Mass Spectrometry for Mapping Three-Dimensional Structures of Proteins and Protein Complexes. J. Mass Spectrom. 2003, 38(12), 1225-1237.

5. Back, J. W.; De Jong, L.; Muijsers, A. O.; De Koster, C. G. Chemical Cross-Linking and Mass Spectrometry for Protein Structural Modeling. J. Mol. Biol. 2003, 331(2), 303-313.

6. Young, M. M.; Tang, N.; Hempel, J. C.; Oshiro, C. M.; Taylor, E. W.; Kuntz, I. D.; Gibson, B. W.; Dollinger, G. High Throughput Protein Fold Identification by Using Experimental Constraints Derived from Intramolecular Crosslinks and Mass Spectrometry. Proc. Natl. Acad. Sci. U.S.A. 2000, 97(11), 5802-5806.

7. Huang, B. X.; Kim, H.-Y.; Dass, C. Probing Three-Dimensional Structure of Bovine Serum Albumin by Chemical Crosslinking and Mass Spectrometry. J. Am. Soc. Mass Spectrom. 2004, 15(8), 1237-1247.

8. Pearson, K. M.; Pannell, L. K.; Fales, H. M. Intramolecular Crosslinking Experiments on Cytochrome $c$ and Ribonuclease A Using an Isotope Multiplet Method. Rapid Commun. Mass Spectrom. 2002, 16(3), 149-159.

9. Lanman, J.; Lam, T. T.; Barnes, S.; Sakalian, M.; Emmett, M. R.; Marshall, A. G.; Prevelige, P. E. Identification of Novel Interactions in HIV-1 Capsid Protein Assembly by High-resolution Mass Spectrometry. J. Mol. Biol. 2003, 325(4), 759-772.

10. Back, J. W.; Sanz, M. A.; De Jong, L.; De Koning, L. J.; Nijtmans, L. G. J.; De Koster, C. G.; Grivell, L. A.; Van Der Spek, H.; Muijsers, A. O. A Structure for the Yeast Prohibiting Complex: Structure Prediction and Evidence from Chemical Crosslinking and Mass Spectrometry. Protein Sci. 2002, 11(10), 2471-2478.

11. Chu, F.; Shan, S.-O.; Moustakas, D. T.; Alber, F.; Egea, P. F.; Stroud, R. M.; Walter, P.; Burlingame, A. L. Unraveling the Interface of Signal Recognition Particle and Its Receptor by Using Chemical Crosslinking and Tandem Mass Spectrometry. Proc. Natl. Acad. Sci. U.S.A. 2004, 101(47), 16454-16459.

12. Kalkhof, S.; Ihling, C.; Mechtler, K.; Sinz, A. Chemical Crosslinking and High-Performance Fourier Transform Ion Cyclotron Resonance Mass Spectrometry for Protein Interaction Analysis: Application to a Calmodulin/Target Peptide Complex. Anal. Chem. 2005, 77(2), 495-503.

13. Ahrends, R.; Kosinski, J.; Kirsch, D.; Manelyte, L.; Giron-Monzon, L. Hummerich, L.; Schulz, O.; Spengler, B.; Friedhoff, P. Identifying an Interaction Site Between MutH and the C-Terminal Domain of MutL by Crosslinking, Affinity Purification, Chemical Coding, and Mass Spectrometry. Nucleic Acids Res. 2006, 34(10), 3169-3180.

14. Huang, B. X.; Dass, C.; Kim, H.-Y. Probing Conformational Changes of Human Serum Albumin Due to Unsaturated Fatty Acid Binding by Chemical Crosslinking and Mass Spectrometry. Biochem. J. 2005, 387(3), 695-702.

15. Huang, B. X.; Kim, H.-Y. Interdomain Conformational Changes in Akt Activation Revealed by Chemical Crosslinking and Tandem Mass Spectrometry. Mol. Cell. Proteom. 2006, 5(6), 1045-1053.

16. Urlaub, H.; Hartmuth, K.; Kostka, S.; Grelle, G.; Luhrmann, R. A General Approach for Identification of RNA-Protein Crosslinking Sites Within Native Human Spliceosomal Small Nuclear Ribonucleoproteins (snRNPs). Analysis of RNA-Protein Contacts in Native U1 and U4/ U6.U5 snRNPs. J. Biol. Chem. 2000, 275(52), 41458-41468.

17. Chen, T.; Jaffe, J. D.; Church, G. M. Algorithms for Identifying Protein Crosslinks Via Tandem Mass Spectrometry. J. Comput. Biol. 2001, 8(6), 571-583.

18. de Koning, L. J.; Kasper, P. T.; Back, J. W.; Nessen, M. A.; Vanrobaeys, F.; Van Beeumen, J.; Gherardi, E.; de Koster, C. G.; de Jong, L. Computer-Assisted Mass Spectrometric Analysis of Naturally Occurring and Artificially Introduced Crosslinks in Proteins and Protein Complexes. FEBS J. 2006, 273(2), 281-291. 
19. Gao, Q.; Xue, S.; Doneanu, C. E.; Shaffer, S. A.; Goodlett, D. R.; Nelson, S. D. Pro-CrossLink Software Tool for Protein Cross-Linking and Mass Spectrometry. Anal. Chem. 2006, 78(7), 2145-2149.

20. Schilling, B.; Row, R. H.; Gibson, B. W.; Guo, X.; Young, M. M. MS2Assign, Automated Assignment and Nomenclature of Tandem Mass Spectra of Chemically Crosslinked Peptides. J. Am. Soc. Mass Spectrom. 2003, 14(8), 834-850.

21. Seebacher, J.; Mallick, P.; Zhang, N.; Eddes, J. S.; Aebersold, R.; Gelb, M. H. Protein Crosslinking Analysis Using Mass Spectrometry, IsotopeCoded Cross-Linkers, and Integrated Computational Data Processing. J. Proteome Res. 2006, 5(9), 2270-2282.

22. Tang, Y.; Chen, Y.; Lichti, C. F.; Hall, R. A.; Raney, K. D.; Jennings, S. F. CLPM: A Crosslinked Peptide Mapping Algorithm for Mass Spectrometric Analysis. BMC Bioinformatics 2005, 6(Suppl. 2), S9.

23. Gaucher, S. P.; Hadi, M. Z.; Young, M. M. Influence of Crosslinker Identity and Position on Gas-Phase Dissociation of Lys-Lys Crosslinked Peptides. J. Am. Soc. Mass Spectrom. 2006, 17(3), 395-405.

24. Raftery, M. J.; Geczy, C. L. Electrospray Low Energy CID and MALDI PSD Fragmentations of Protonated Sulfinamide Crosslinked Peptides. J. Am. Soc. Mass Spectrom. 2002, 13(6), 709-718.

25. Hunt, D. F.; Yates, J. R., III; Shabanowitz, J.; Winston, S.; Hauer, C. R. Protein Sequencing by Tandem Mass Spectrometry. Proc. Natl. Acad. Sci. U.S.A. 1986, 83(17), 6233-6237.

26. Biemann, K.; Martin, S. A. Mass Spectrometric Determination of the Amino Acid Sequence of Peptides and Proteins. Mass Spectrom. Rev. 1987, 6(1), 1-76.

27. Huang, Y.; Triscari, J. M.; Tseng, G. C.; Pasa-Tolic, L.; Lipton, M. S.; Smith, R. D.; Wysocki, V. H. Statistical Characterization of the Charge State and Residue Dependence of Low-Energy CID Peptide Dissociation Patterns. Anal. Chem. 2005, 77(18), 5800-5813.

28. Tabb, D. L.; Smith, L. L.; Breci, L. A.; Wysocki, V. H.; Lin, D.; Yates, J. R., III. Statistical Characterization of Ion Trap Tandem Mass Spectra from Doubly-Charged Tryptic Peptides. Anal. Chem. 2003, 75(5), 1155-1163.

29. Kapp, E. A.; Schutz, F.; Reid, G. E.; Eddes, J. S.; Moritz, R. L.; O'Hair, R. A.; Speed, T. P.; Simpson, R. J. Mining a Tandem Mass Spectrometry Database to Determine the Trends and Global Factors Influencing Peptide Fragmentation. Anal. Chem. 2003, 75(22), 6251-6264.

30. Dongre, A. R.; Jones, J. L.; Somogyi, A.; Wysocki, V. H. Influence of Peptide Composition, Gas-Phase Basicity, and Chemical Modification on Fragmentation Efficiency: Evidence for the Mobile Proton Model. J. Am. Chem. Soc. 1996, 118(35), 8365-8374.

31. Tsaprailis, G.; Nair, H.; Somogyi, A.; Wysocki, V. H.; Zhong, W.; Futrell, J. H.; Summerfield, S. G.; Gaskell, S. J. Influence of Secondary Structure on the Fragmentation of Protonated Peptides. J. Am. Chem. Soc. 1999, 121(22), 5142-5154.

32. Loo, J. A.; Edmonds, C. G.; Smith, R. D. Tandem mass spectrometry of very large molecules. II. Dissociation of Multiply-Charged Proline-
Containing Proteins from Electrospray Ionization. Anal. Chem. 1993, 65(4), 425-438.

33. Tsaprailis, G.; Somogyi, A.; Nikolaev, E. N.; Wysocki, V. H. Refining the Model for Selective Cleavage at Acidic Residues in Arginine-Containing Protonated Peptides. Int. J. Mass Spectrom. 2000, 195/196, 467-479.

34. Papayannopoulos, I. A. The Interpretation of Collision-Induced Dissociation Tandem Mass Spectra of Peptides. Mass Spectrom. Rev. 1995, 14(1), 49-73

35. Reid, G. E.; Wu, J.; Chrisman, P. A.; Wells, J. M.; McLuckey, S. A. Charge State-Dependent Sequence Analysis of Protonated Ubiquitin Ions Via Ion Trap Tandem Mass Spectrometry. Anal. Chem. 2001, 73(14), $3274-$ 3281.

36. Reid, G. E.; Stephenson, J. L., Jr.; McLuckey, S. A. Tandem Mass Spectrometry of Ribonuclease A and B: N-Linked Glycosylation Site Analysis of Whole Protein Ions. Anal. Chem. 2002, 74(3), 577-583.

37. Sullivan, A. G.; Brancia, F. L.; Tyldesley, R.; Bateman, R.; Sidhu, K.; Hubbard, S. J.; Oliver, S. G.; Gaskell, S. J. The Exploitation of Selective Cleavage of Singly-Protonated Peptide Ions Adjacent to Aspartic Acid Residues Using a Quadrupole Orthogonal Time-of-Flight Mass Spectrometer Equipped with a Matrix-Assisted Laser Desorption/Ionization Source. Int. J. Mass Spectrom. 2001, 210/211(1/3), 665-676.

38. Wysocki, V. H.; Tsaprailis, G.; Smith, L. L.; Breci, L. A. Mobile and Localized Protons: A Framework for Understanding Peptide Dissociation. J. Mass Spectrom. 2000, 35(12), 1399-1406.

39. Burlet, O.; Orkiszewski, R. S.; Ballard, K. D.; Gaskell, S. J. Charge Promotion of Low-Energy Fragmentations of Peptide Ions. Rapid Commun. Mass Spectrom. 1992, 6(11), 658-662.

40. Summerfield, S. G.; Gaskell, S. J. Fragmentation Efficiencies of Peptide Ions Following Low Energy Collisional Activation. Int. J. Mass Spectrom. Ion Processes 1997, 165/166, 509-521.

41. Harrison, A. G.; Tn, Y.-P. Ion Chemistry of Protonated Aspartic Acid Derivatives. J. Mass Spectrom. 1998, 33(6), 532-542.

42. Yu, W.; Vath, J. E.; Huberty, M. C.; Martin, S. A. Identification of the Facile Gas-Phase Cleavage of the Asp-Pro and Asp-Xxx Peptide Bonds in Matrix-Assisted Laser Desorption Time-of-Flight Mass Spectrometry. Anal. Chem. 1993, 65(21), 3015-3023.

43. Gu, C.; Tsaprailis, G.; Breci, L.; Wysocki, V. H. Selective Gas-Phase Cleavage at the Peptide Bond C-Terminal to Aspartic Acid in FixedCharge Derivatives of Asp-Containing Peptides. Anal. Chem. 2000, 72(23), 5804-5813.

44. Loo, J. A.; Edmonds, C. G.; Smith, R. D. Primary Sequence Information from Intact Proteins by Electrospray Ionization Tandem Mass Spectrometry. Science 1990, 248(4952), 201-204.

45. Schwartz, B. L.; Bursey, M. M. Some Proline Substituent Effects in the Tandem Mass Spectrum of Protonated Penta-Alanine. Biol. Mass Spectrom. 1992, 21(2), 92-96.

46. Vaisar, T.; Urban, J. Probing the Proline Effects in CID of Protonated Peptides. J. Mass Spectrom. 1996, 31(10), 1185-1187. 